\title{
A Survey on Vocabulary Learning Strategies: A Case of Iranian EFL University Students
}

\author{
Seyyed Mohammad Reza Amirian \\ Hakim Sabzevari University, Iran \\ Zahra Heshmatifar \\ Hakim Sabzevari University, Iran
}

\begin{abstract}
This study aims at investigating what strategies are more or less common for learning vocabulary among EFL university students at Hakim Sabzevari University in Iran. A questionnaire adapted from the taxonomy of vocabulary learning strategies (VLS) developed by Schmitt (1997) was administered to 74 EF L students (18 males and 56 females).Moreover, semi-structured interviews were also carried out with ten students who completed the written questionnaire to obtain more information about their beliefs and attitudes dealing with vocabulary learning strategies. The results revealed the following order of strategy use by the students from the most frequent to the least frequent one: determination (DET), cognitive (COG), memory (MEM), metacognitive (MET), and social strategies (SOC). In particular, findings indicated that guessing from context and dictionary use strategies were the most popular strategies, while asking the teacher or peers for meaning were rarely used.
\end{abstract}

Index Terms - VLS, determination, cognitive, metacognitive, memory, social strategies

\section{INTRODUCTION}

Many research studies (Cohen, 2007; Oxford, 2002; Prichard, 2008) have pointed out that language learning strategies play a very vital role in foreign language learning. Oxford (1994) refers to learning strategies as specific actions, behaviors or techniques students use to improve their progress in comprehending and producing $\mathrm{L} 2$. He notes that these strategies can make learning easier, faster, more fun, independent, and efficient.

Cohen (2007) speaks of language learning strategies as some techniques including three factors: action, goal, and situation. Consequently, the word strategy indicates some degree of awareness on the part of the learner. If foreign language learners are equipped with strategies such as vocabulary learning strategies, they can be much more successful language learners because vocabulary learning strategies make students autonomous and enable them to take responsibility of their own learning (Oxford, 1990). As Benson (2001) puts it explicit teaching of strategies can help EFLESL learners to become more independent learners. Since the late 1970s, there have been many researchers focusing their attention on vocabulary learning strategies as a vital issue among different strategies of language learning. Obviously, learning and using these strategies will lead to vocabulary development of learners. Additionally, considering vocabulary instruction as a broad area, the teachers become aware of their methodology by obtaining an overall pattern of learners' vocabulary learning strategies.

This research study makes attempt to address the following research questions:

1. What are the most common vocabulary learning strategies used by Iranian college EFL learners?

2. What are the least common vocabulary learning strategies used by Iranian college EFL learners?

\section{BACKGROUND}

Learn ing vocabulary is considered as an indispensable part of language learning and production as limited knowledge of vocabulary results in learner difficulties in production as well as comprehension of language. Concerning the comple xity of this issue, vocabulary learning strategies, as a part of language learning strategies, seem to be very crucial in language learning and consequently being aware of these strategies is important for both teachers and students. Fan (2003) argues that all vocabulary learn ing strategies consist of five steps: (1) to encounter the word (2) to get a visual or auditory image of the word. (3) to learn the meaning of the word (4) to make a strong memory link between the forms and the meanings of the words and (5) to use the word.

A number of researchers (Gu \& Johnson, 1996; O’Malley \& Chamot 1990; Oxford, 1990; Schmitt, 2000) have proposed various classifications of vocabulary learning strategies. However, for the purpose of this study, the taxonomy developed by Schmitt (1997) has been used. He proposes two aspects of vocabulary learning strategies: discovery strategies and consolidation strategies. Discovery strategies refer to strategies used to uncover the meaning of the words presented to the learner for the first time while consolidation strategies are applied to help the learner internalize the mean ing when he/she encounters the word afterwards. 
These strategies are subdivided into five categories as determination strategies (DET) referring to individual learn ing strategies which help learners to discover the meaning of words by themselves without getting any help from their teachers or peers. Social strategies (SOC) which engage learners in interaction with others, me mory strategies (MEM) which involve learners in learning the newly-learned word by relating their current or background knowledge with the new word. Cognitive strategies (COG) in which learners are not involved in mental processing rather th ey are engaged in more mechanical processing, and metacognitive (MET) strategies which are strategies concerning processes such as decision-making, monitoring and evaluating learner's progress.

Previous research on vocabulary learning strategies has yielded insightful results. A study conducted by Ahmad (1989) showed that successful undergraduate Sudanese students used dictionary use and note taking strategies as two popular learning strategies. The findings of another similar study conducted by Gu and John son (1996) on 850 Chinese college students revealed that there was a significant relationship between vocabulary learning strategies, language proficiency, and vocabulary breadth. Interestingly, there was a positive correlation between learners' scores and these strategies: dictionary use, guessing from context, and note-taking. However, they found that visually repeated words had a negative correlation with the size of vocabulary and general proficiency.

Still, in another survey carried out in Japan by Sch mitt (1997) among 600 high school, college and adult learners, the researcher found that the most frequently used strategies were dictionary use, oral and written repetition, word spelling, and contextual guessing, whereas semantic map, the key word method, and first language cognates were used less frequently. There was also some evidence that more proficient learners were inclined to use more complex and mean ing-centered strategies than less proficient learners.

In another research project, the effects of explicit teaching of keyword strategy among 40 students were investigated by Lawson and Hogben (1998). The results manifested that most of the learners are familiar with different strategies of vocabulary learning. Moreover, they found that repetition was the most commonly used strategy.

Having classified the vocabulary learning strategies in a systematic way, Kudo (1999) claimed that many strategies were seldom used. He concluded that the most and the least common vocabulary learning strategies in L2 were rotelearning and key-word technique, respectively. Fan (2003) also studied 1067 college students in Hong Kong and recognized that they did not make use of key word technique and management strategy while they utilized dictionary and contextual guessing strategies.

In a rather recent study, Marin-Marin (2005) examined the utilization of vocabulary learning strategies by $150 \mathrm{EFL}$ students at the University of Quintana. It was found that guessing meaning from context, using dictionary to check the meaning and repeating silently were the most commonly used strategies and keeping notes on electric devices, using electric dictionaries, and recording words on audiotapes were the least commonly used strategies. Additionally, Marin Marin (2005) explored that contextual guessing, dictionary use and silent repetition were utilized frequently by EFL learners at Quintana University. In contrast, electronic note keeping, using electronic dictionary and using vocabulary tape- recording were rarely used.

In a more recent experiment, Arjomand and Sharififar (2011) made effort to explore the relationship between vocabulary learning strategies and gender among Iranian EFL learners. They concluded that cognitive strategy was the most commonly used strategy, while social strategy was the least frequently used one. Furthermore, with respect to gender, they claimed that cognitive/ metacognitive and social strategies were respectively the most and the least commonly used ones. Considering the contradictory results of the vocabulary strategy studies, particularly at tertiary level, the results of this study may have a significant contribution to our understanding of these strategies and the way they are applied by Iranian EFL university students.

\section{METHOD}

\section{A. Participants}

A total of 74 Iranian students from Hakim Sabzevari University participated in the study, eighteen postgraduate students majoring in TEFL (teaching English as foreign language), and fifty six undergraduate students majoring in English literature. Twenty one were males and fifty three were females. The age of the students ranged from 19 to 34 . The demographic information of participants is shown in Table 1.

TABLE 1

DESCRIPTION OFPARTICIPANTS

\begin{tabular}{|l|l|l|}
\hline Variables & Category & number \\
\hline Gender & male & 21 \\
\cline { 2 - 3 } & Female & 53 \\
\cline { 2 - 3 } & Total & 74 \\
\hline \multirow{4}{*}{ Course } & Undergraduate & 56 \\
\cline { 2 - 3 } & Postgraduate & 18 \\
\cline { 2 - 3 } & Total & 74 \\
\hline
\end{tabular}

\section{B. Instrument}


To identify the vocabulary learning strategies the participants employed, the current study made use of the questionnaire adapted from Schmitt's (1997) taxonomy of vocabulary learning strategies (see Appendix). All 40 items in the questionnaire were reorganized and classified under 5 different groups of strategies as eleven statements on memory strategies (items 1-11), nine statements on determination strategies (item 12-20), six statements on social strategies (items 21-26), nine statements on cognitive strategies (items 27-35), and five statements on metacognitive strategies (items 36-40) (see Table 2). The frequency of use were measured by 5-point likert-scale from 1(never) to 5(always). Statistical analys is was carried out using The Statistical Package for the Social Sciences (SPSS, version 17.0). Furthermore, a number of semi-structured interviews were conducted to validate the outcomes and also to get familiar to students' attitudes towards vocabulary learning strategies.

TABLE 2

DESCRIPTIONS OF THE CATEGORIES OF VOCABULARY LEARNING STRATEGIES

\begin{tabular}{|l|l|}
\hline Strat egy Cat egory & Strat egy Item \\
\hline Memory Strategies (MEM) & $1-11$ \\
\hline Determinat ion Strategies (DET) & $12-20$ \\
\hline Social Strategies (SOC) & $21-26$ \\
\hline Cognitive Strat egies (COG) & $27-35$ \\
\hline Metacognitive Strategies (MET) & $36-40$ \\
\hline
\end{tabular}

\section{Procedure}

The questionnaire had a time limit of 20 minutes. It was administered on December $18^{\text {th }}, 2011$. Before filling out the questionnaire, students were told that their participation was voluntary. They were also asked to answer as honestly as possible. Since all the participants majored in English, the questionnaire was not translated into the learners' mother tongue (i.e., Farsi). The survey was kept anonymous to counteract the tendency of the participants to answer in a way they think the researchers would like. The participants were asked to indicate if they used the particular strategy. Moreover, ten students were selected for interviews as representatives from the same 74 students used for the questionnaire. All interviews were conducted in Farsi, the first language of the interviewees, to assure their comprehension of the questions.

\section{RESULTS}

Having analyzed the interview and questionnaire data, the researchers tried to report the findings based on the research questions. To describe the most and least frequently used vocabulary learning strategies, descriptive statistics, including means and standard deviations of the five categories and their subdivisions are employed. The results of descriptive analysis are presented in Table 3. As the table indicates, determination strategies $(\mathrm{M}=31.76 ; \mathrm{SD}=5.42)$ are reported as the most frequently-used of the five vocabulary learning strategies, followed by cognitive strategies $(\mathrm{M}=26.95 ; \mathrm{SD}=4.16)$, me mory strategies $(\mathrm{M}=25.5 ; \mathrm{SD}=4.28)$, metacognitive strategies $(\mathrm{M}=13.92 ; \mathrm{SD}=3.51)$, and social strategies $(\mathrm{M}=1066 ; \mathrm{SD}=3.73)$.

TABLE 3

DESCRIPTIVE STATISTICS FOR EACH VOCABULARY LEARNING STRATEGY $\quad \mathrm{N}=74$

\begin{tabular}{|l|l|l|l|l|l|}
\hline Strategy & Min. & Max. & M & SD & Rank \\
\hline Determination & 9 & 45 & 31.76 & 5.42 & 1 \\
\hline Cognitive & 9 & 44 & 26.95 & 4.16 & 2 \\
\hline Memory & 11 & 49 & 25.5 & 4.28 & 3 \\
\hline Metacognitive & 5 & 22 & 13.92 & 3.51 & 4 \\
\hline Social & 6 & 21 & 10.66 & 3.73 & 5 \\
\hline
\end{tabular}

When it comes to the most and the least frequently used vocabulary learning strategies with respect to in dividual items, Table 4 shows that the most frequently used strategies spread across the two categories of vocabulary learning strategies, namely determination strategies (DET) and cognitive strategies(COG). The highest mean $(\mathrm{M}=4.21)$ was achieved by strategy item 14 "I guess from textual context". Strategy Item 16 "I consult a monolingual dictionary" reaches the second highest mean of 3.98 followed by verbal repeating (Ite m 29; M=3.91), analy zing the parts of speech (Item 20; M=3.84), studying the word sound (Item 7; M=3.80), and keeping a vocabulary notebook (Item 34; M=3.78).

TABLE 4

TOP 6 OF THE MOST FREQUENTLY USED VOCABULARY LEARNING STRATEGIES

\begin{tabular}{|l|l|l|l|l|l|}
\hline Rank & Description & Item & Category & Mean & SD \\
\hline 1 & I guess from textual context & 14 & DET & 4.21 & 1.00 \\
\hline 2 & I consult a monolingual dict ionary & 16 & DET & 3.98 & .93 \\
\hline 3 & I repeat the word verbally & 29 & COG & 3.91 & .98 \\
\hline 4 & I analyze the part s of speech & 20 & DET & 3.84 & .97 \\
\hline 5 & I study the sound of the word & 7 & MEM & 3.80 & 1.03 \\
\hline 6 & I keep a vocabulary notebook & 34 & COG & 3.78 & .93 \\
\hline
\end{tabular}


The results shown in Table 5 reveal that skipping or passing the new word (Item 39; $\mathrm{M}=1.56$ ), asking the teacher for making a sentence (Item 3; M=1.72), using flash cards (Item 35; M=1.80), asking the teacher for $\mathrm{L} 1$ translation (Item 21; $\mathrm{M=1.83}$ ), putting English labels for physical objects (Item 33; M=1.98), and reme mbering the in itial letter (Item 11, $\mathrm{M}=1.99$ ) were determined as the least frequently used strategies.

TABLE 5

TOP 6 OF THE LEAST FREQUENTLY USED VOCABULARY LEARNING STRATEGIES

\begin{tabular}{|l|l|l|l|l|l|}
\hline Rank & Description & Item & Cat egory & Mean & SD \\
\hline 1 & I skip or pass the new word & 39 & MET & 1.56 & .80 \\
\hline 2 & I ask the teacher for making a sentence & 3 & SOC & 1.72 & 1.02 \\
\hline 3 & I use flash cards & 35 & MET & 1.80 & .83 \\
\hline 4 & I ask the teacher for L1 translation & 21 & SOC & 1.83 & .99 \\
\hline 5 & I put English labels for phy sical objects & 33 & COG & 1.98 & 1.00 \\
\hline 6 & I remember word's initial letter & 11 & MEM & 1.99 & .93 \\
\hline
\end{tabular}

In order to validate the results and elicit specific information of students' attitudes about vocabulary learning strategies, semi-structured interviews were carried out with 10 students. They were asked to answer the open-ended questions. The results of which are stated below. The question directed to seek "What are the most and the least frequently used strategies of vocabulary learning among Hakim Sabzevari EFL students and why?" Nine out of ten interviewees $(\mathrm{N}=9 ; 90 \%)$ stated that they use monolingual dictionary to discover the meaning of a new word. They claimed that using monolingual dictionary helps them to learn even more words because every item in the dictionary is explained or illustrated. $80 \%(\mathrm{~N}=8)$ of total ten interviewees pointed out that another most preferred vocabulary learning strategy was guessing from context. They added that this is due to the medium role of foreign language in reading comprehension of their textbooks. They noted that words need to be repeated in order to be studied, and different texts provide a context that helps them figure out the meaning of words they do not know. Consequently, this contextualized learning deepens their understanding of words and they learn which words go together as well. The third most commonly used strategy reported by $60 \%(\mathrm{~N}=6)$ respondents was "I make a list of new words and memorize them". They pointed to the benefits of word lists as they are made by learners themselves based on their needs and their interests. Less than half of students $(\mathrm{N}=4 ; 40 \%)$ stated that they connect the new word to its synonyms and antonyms to expand the size of their vocabulary. The social strategy "I ask my teacher for L1 translation" was reported to use rarely $(\mathrm{N}=2 ; 20 \%)$ by the respondents. Similarly, "I ask my classmates for meaning" had the minimum percentage $(\mathrm{N}=1 ; 10 \%)$ compared to other strategies since they thought learning vocabulary individually can be more help ful than in the g roup. The responses to the open-ended interview are shown in Table 6.

TABLE 6

THE MOST AND THE LEAST-REPORTED VOCABULARY LEARNING STRATEGIES $\quad \mathrm{N}=10$

\begin{tabular}{|l|l|l|l|}
\hline Strategy description & Rank & Category & Percentage \\
\hline I use a monolingual dictionary & 1 & DET & $90 \%$ \\
\hline I guess the meaning from context & 2 & DET & $80 \%$ \\
\hline I make a list of words and memorize them & 4 & COG & $60 \%$ \\
\hline I connect the words to the synonyms/antonyms & 3 & MEM & $40 \%$ \\
\hline I ask my teacher for L1 strat egy & 5 & SOC & $20 \%$ \\
\hline I ask my classmates for meaning & 6 & SOC & $10 \%$ \\
\hline
\end{tabular}

\section{DISCUSSION}

The major findings of the present study is that among the five vocabulary learning strategies based on Schmitt's taxonomy, Determination Strategies were reported as the most frequently-used strategies, followed by Cognitive Strategies as the second most frequently-used strategies, Memory Strategies as the third most frequently-used strategies, Metacognitive Strategies as the fourth most frequently-used strategies, and Social Strategies were the least frequentlyused strategies. Thus, "asking teacher's L1 translation" and "asking the classmates for meaning" were ranked at the bottom of Table 6. This result seemed to be consistent with the results from Arjo mand and Sharififar's (2011) study with Iranian EFL freshman students who used social strategies least frequently.

The most plausible explanation for this is sue is that the nature of vocabulary learning is considered as an individual or asocial process. Therefore, students resist asking others' assistance for the meaning of new words. This finding also aligns with the findings of a study done by Kafipour (2006) who emphasized that learning in an EFL environ ment was a major reason why social strategies were not widely used, that is, in an EFL environment there is no need to negotiate the meaning of the word in communication situations. He further explained that He further explained that what seems to be essential is the active engagement of participants in different learning contexts, such as class room activities. Another weakness is due to educational system in Iran which is known as teacher-oriented. Teachers are in front of the classroom and provide all knowledge students need. Teachers provided the information through lecturing and the students should just listen and take note. Such teaching procedure did not have any place for group work or discussion in classroom. 
Findings of the present study also revealed that guessing from context $(M=4.21)$ and dictionary strategies $(M=3.98)$, as the most preferred ones, were employed by $80 \%$ and $90 \%$ of the respondents, respectively and were considered as two top strategies (see Table 4 and Table 6). This finding of the current study echoes the results of Marin-Marin (2005) that some proficient learners used more guessing from context and dictionary strategies than any other type. Similarly, this result is in agreement with the other studies on guessing the meanings from the context raised by Gu and Johnson (1996), and Schmitt (1997). Data analysis also revealed that memory strategies are the third frequently used strategies. This finding was unlike the findings of Kafipour's (2010) study who found memory strategies as the most frequently used strategies by Iranian EFL undergraduate students. The reason is likely due to the postgraduate students as more successful learners who tend to employ a wide range of vocabulary learning strategies rather than just me morization and rote learning. This view is in line with Schmitt's (1997) claim that there is some evidence that more advanced learners tended to use more complex and meaning-focused strategies than less advanced learners.

\section{CONCLUSION}

This study investigated the most and least frequently used strategies of vocabulary learning strategies by collage EFL students at Hakim Sabzevari University. The major finding of this research was that determination strategies such as guessing from context and consulting a dictionary were the most popular strategies, whereas social strategies were the least popular. The findings of this study also revealed that the majority of students did not use certain vocabulary learning strategies such as semantic maps and discovering meaning through group work activity. Actually, it seems that not many students are familiar with these strategies. Therefore, the present study suggests that it is vitally important for students to be trained on vocabulary learning strategies. Similarly, Nation (2001) maintains that there is enough evidence that explicit instruction of strategies can improve learners' strategic knowledge. Furthermore, strategy train ing leads to learner autonomy. It helps them to become aware of their own preferences and habits and feel responsible for own learning.

Even though the findings of this study can enlighten language teachers an offer them a deeper understanding as to how to design more effective vocabulary learning tasks to better fit Iranian collage EFL learners at different levels, it does not seem to be conclusive and carrying out more elaborate studies with much larger population seems to be necessary.

\section{REFERENCES}

[1] Ahmad, M. (1989). Vocabulary learning strategies. In P. Meara (Ed.), Beyond words. London: CILT. 3-14.

[2] Arjomand, M., \& Sharififar, M. (2011). The most and least frequently used vocabulary learning strategies among Iranian EFL freshman students and its relationship to gender. Iranian EFL Journal, 7(1), 90-100.

[3] Benson, P. (2001). Teaching and researching: Autonomy in lan guage learning. London: Longman.

[4] Brown, C., \& Payne, M. E. (1994). Five essential steps of processes in vocabulary learning. A Paper presented at the TESOL Convention. Baltimore, Md.

[5] Cohen, A. (2007). Coming to terms with language learner strategies: Surveying the experts. In A. Cohen, \& E. Macro (Eds.), Language learning strategies: 30 years of research and practice. Oxford: Oxford University press. 29- 45.

[6] Fan, M. (2003). Frequency of use, perceived usefulness, and actual usefulness of second language vocabulary strategies: A study of Hong Kong learners. The Modern Language Journal, 87(2), 222-241.

[7] Griffiths, C. (2003). Patterns of language learning and strategy use. System, 31, 367-383.

[8] Gu,Y., \& Johnson, R. K. (1996). Vocabulary learning strategies and language learning out-comes. Language Learning. 46(6), 643-679.

[9] Hsiao, T., \& Oxford, R. (2002). Comparing theories of language learning strategies: A confirmatory factor analysis. The Modern Language Journal, 86(3), 368-383.

[10] Kafipour, R. (2006). The Application of Language Learning Strategies by Turkish-, Kurdish-, and Persian-Speaking EFL Students. Shiraz: Islamic Azad University.

[11] Kafipour, R. (2010). Vocabulary Learning Strategies, Vocabulary Knowledge and Reading Comprehension of EFL Undergraduate Students in Iran. (Unpublished doctoral dissertation). University Putra Malaysia, Malay sia.

[12] Kafipour, R., \& Sarani, A. (2008). The relationship between extroversion introversion/ tendencies of Iranian BA students of English and their English oral production. ELT profession: Challenges and prospects. Lincom GmbH: Muenchen.

[13] Kudo, Y. (1999). L2 vocabulary learning strategies. University of Hawaii, Manoa. Retrieved November 10, 2011, from http://www.111.hawaii.edu/nflc/Networks /NW14/.

[14] Lawson, M. J., \& Hogben, D. (1998). Learning and recall of foreign-language vocabulary: Effects of a key word strategy for immediate and delayed recall. Language and Institution, 8(2), 179-194

[15] Nation, I. S. P. (2001). Learning vocabulary in another lan guage. Cambridge: Cambrid ge University Press.

[16] Nassaji, H. (2003). L2 vocabulary learning through context: strategies, knowledge sources, and their relationship with success in L2 lexical inferencing. TESOL Quarterly, 37(4), 675-70.

[17] Nunan, D. (2002). Learning strategy training in the classroom: An action research study. In J.C. Richards, \& A.W.

[18] O' Malley, J., \& Chamot, A. (1990). Learning strategies in second language acquisition. Cambridge: Cambridge University Press.

[19] Oxford, D. (2002). Language learning strategies in a nutshell: Updated ESL suggestions. In Richards, J. C., \& Renadya, A. W. (Eds.), Methodology in languages teaching, An anthology of current practice. Cambridge: Cambridge university press. 124-132.

[20] Oxford, R. (1990). Language learning strategies: What every teacher should know. Boston: Heinle \& Heinle. 
[21] Oxford, R. (1994). Language Learning Strategies: An Update. ERIC Digest. Retrieved December 16, 2011, from EBSCO Host online database, ERIC number ED376707.

[22] Oxford, R. (1995). Gender differences in language learning styles: What do you mean? In J. Reid (Ed.), Learning styles in the ESL /EFL classrooms. Boston: Helinle \& Helinle. 3-18.

[23] Prichard, C. (2008). Evaluating L2 readers' vocabulary strategies and dictionary use. Reading in Foreign Language, 20(2), 21623.

[24] Schmitt, N. (1997). Vocabulary learning strategies. In N. Schmitt \& M. McCarthy (Eds.), Vocabulary: description, acquisition and pedagogy (pp.199-228). Cambridge: Cambrid ge University Press.

[25] Schmitt, N. (2000). Vocabulary in lan guage teaching. Cambridge University Press, Cambridge.

Seyyed Mohammad Reza Amirian got his PhD in TEFL from the University of Tehran. Currently, he is teaching undergraduate and graduate courses at Hakim Sabzevari University. He has published several articles and books and presented in many conferences. His research interest includes test bias and fairness, dy namic assessment, teaching and testing language skills, vocabulary assessment and ESP.

Zahra Heshmatifar is a PhD student of TEFL at Hakim Sabzevari University, Iran. She teaches English at Sabzevar high schools and also teaches general English courses at Hakim Sabzevari University. Her research interest includes vocabulary assessment and sociolinguistics. 